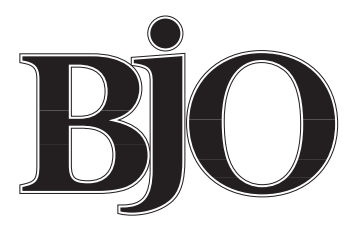

British Journal of Ophthalmology

One of the greatest challenges facing world ophthalmology today remains the unacceptably high prevalence of operable cataract blindness in the developing world. The establishment of national and international cataract programmes, frequently funded and supported by international agencies, has achieved a steady increase in the number of cataract operations performed, but current levels remain too low to tackle the backlog of cataract blind, estimated to be 16-20 million, and to stem the rising world incidence consequent on the aging population.

As understanding grows of the dynamics of the problem of cataract blindness, it is increasingly realised that solutions resting on cataract numbers alone are insufficient, and that strategic planning is needed to effect change across a complex web of interrelated constraints if the goal of a high volume sustainable cataract programme is to be achieved.

Fundamental are questions of quality of surgical outcome and cost. As eloquently illustrated by Pokharel et al in two papers in this issue of the journal (pp 600 and 606), cataract programme strategies based on intracapsular cataract extraction (ICCE) and the provision of aphakic spectacles, even when the service is free, fail to significantly affect the blindness prevalence. This is not only because cataract coverage is insufficient, but also because an estimated 10-15\% of patients remain socially blind (visual acuity <3/60) after the surgery. ${ }^{1}$ Apart from the failures due to incorrect diagnosis (a patient blind with cataract but not because of cataract) and operative complications, this can be attributed to the difficulties of the refractive correction of aphakia. When visual outcome includes an assessment of quality of vision and visual function, a more encompassing and realistic measure than Snellen visual acuity, it is even more apparent that the results of ICCE/spectacle correction are inadequate. It has been estimated, for example, that to function as well as a pseudophake with $6 / 18$ vision, a corrected aphake must have a visual acuity of $6 / 6$ or better. ${ }^{2}$ Postoperative aphakia is furthermore inappropriate in the unilaterally blind. The visual outcome failure of traditional cataract programmes to correct blindness is reflected by the estimated $30-50 \%$ of aphakic patients who chose not to wear the glasses provided free nor to replace them when they became lost or damaged..$^{13}$

Given the importance of quality of outcome on the effectiveness of the cataract surgery to correct blindness, there are now strong advocates for the introduction of treatment strategies that involve insertion of an intraocular lens (IOL). Many workers have reported the efficacy and safety of high volume cataract surgery with IOL insertion, both anterior and posterior chamber, in clinic and outreach eye camp settings in the developing world..$^{4-6}$ Previous constraints of cost and affordable technology that impeded the application of this technique, long adopted in the Western world, to the developing world have now been largely overcome. High quality one piece posterior chamber intraocular lenses are now available at a unit cost of US $\$ 10$ as are sturdy portable microscopes. Of fundamental importance are skilled medical staff, be they doctors or cataract surgeon "technicians", and priority should be increasingly given by national health services and international organisations on training and skill transfer. This can be achieved most effectively by programmes which "train the trainers", local medical staff, who can then provide ongoing supervision and support.

Fundamental to the sustainability of cataract programmes and to overcoming patient barriers to the surgery are questions of cost. There are now several highly successful models of cataract programmes based on cost recovery, particularly that in Aravind, India. ${ }^{7}$ These models take into consideration the unit cost of surgery including transport and disposables, as well as operational fixed costs, and function through the charging of a scale of patient fees and incorporating subsidies for the destitute. They aim to cure cataract before severe blindness has developed and while the patient is economically productive with some resources to afford the surgery. For these models to work, operational and infrastructure aspects must be addressed, most importantly the management of cataract services to optimally utilise existing resources.

Patient barriers to cataract surgery are also important. Although some of these barriers, such as availability and proximity of surgical facilities, can be addressed through a cataract programme which includes outreach, the chief barriers of ignorance, low motivation, and impoverishment remain difficult to overcome. Educative and advertising drives are important but marketing relies on quality of surgical outcome: perhaps the most effective motivator is a previously blind patient following a successful vision restorative operation who educates and motivates others.

The challenge remains in cataract blindness programmes to increase operation numbers, while improving the quality of the visual outcome and decreasing the cost. It is a challenge worth undertaking, by ophthalmologists in the Western world, as well as those in the developing world.

JENNIFER ARNOLD

Consultant ophthalmologist, Aberdeen Royal Infirmary and medical director, Fred Hollows Foundation Australia 
1 Ellwein LB, Kupfer C. Strategic issues in preventing cataract blindness in developing countries. Bull World Health Organ 1995;73:681-90.

2 Fletcher AE, Ellwein LB, Selvaraj S, et al. Measurements of vision function and quality of life in patients with cataracts in southern india. Arch and quality of life in patien

3 Hogeweg M, Sapkota YK, Foster A. Acceptability of aphakic correction: results from Karnali eye camps in Nepal. Acta Ophthalmol 1992;70:407-12. 4 Civerchia L, Ravindran RD, Apoorvananda SW, et al. High-volume intraocular lens surgery in a rural eye camp in India. Ophthalmic Surg Lasers $1996 ; 27: 200-8$
5 Cook NJ. Evaluation of high volume extracapsular cataract extraction with posterior chamber lens implantation in Sierra Leone, West Africa. $\mathrm{Br} \mathcal{F}$ Ophthalmol 1996;80:698-701.

6 Henning A, Evans JR, Pradhan D, et al. Randomised controlled trial of anterior chamber intraocular lenses. Lancet 1997;349:1129-33.

7 Natchiar G, Robin AL, Thulasiraj RD. Attacking the backlog of India's curable blind. The Aravind eye hospital model. Arch Ophthalmol 1994;112: 987-93.

\section{Do patients with age related maculopathy and cataract benefit from cataract surgery?}

"When I consider how my light is spent, Ere half my days, in this dark world and wide" wrote Milton in the sonnet "On His Blindness" when life expectancy was much shorter than it is as we approach the millennium. By the end of this century $6.5 \%$ of the population of the European Union will be aged 75 and over. ${ }^{2}$ Evans and Wormald ${ }^{3}$ have shown an increase in blind registrations attributed to age related maculopathy (ARM) in the order of $30-40 \%$ from 1950 to 1990 . The Melton Mowbray study ${ }^{4}$ has shown prevalence rates for any ARM of between $82 \%$ and $86 \%$ with drusen found in $72.8 \%$ of the population aged $77-90$. This is the same age group that develops cataract, and to complicate matters further the Beaver Dam study showed that nuclear sclerosis was associated with increased odds of early ARM. ${ }^{5}$

Pollack et $a l^{6}$ found that progression of ARM occurred more often in eyes after cataract surgery compared with fellow eyes, with the risk factors identified those of male sex and soft drusen. They have postulated along with others that the presence of a cataract may protect the eye from phototoxic injury in the presence of ARM but van der Schaft and colleagues ${ }^{7}$ did not find anything to confirm this.

If we are going to offer cataract surgery what do we say to the patients to provide them with realistic expectations? I was greatly helped with the answer to this question by reading the paper by Shuttleworth et al in this issue of the $B F O$ (p 611). I now tell patients with coexisting ARM that, following surgery, there is a two thirds chance that they will feel the operation has been worthwhile with a one third chance that they will feel the operation has not been worthwhile. Shuttleworth and colleagues admit that the presence of ARM is lower in their study with only $9 \%$ of patients undergoing cataract surgery during that period having pre-existing ARM. This paper would have helped even more if the authors had been able to identify predictors of surgical outcome. However, they propose a prospective study which will lead to the development of guidelines for the management of patients with cataract and ARM.
Should we expect patients with cataract and ARM to undergo an operation when there is a one third chance that they will not feel the surgery has been worthwhile. Shuttleworth and colleagues' paper shows that $17 \%$ had mixed feelings and $17 \%$ thought it not worthwhile. We know from other work on patient satisfaction with visual function following cataract surgery that approximately $10 \%$ in all series of patients undergoing cataract surgery are not entirely happy with the outcome. If this study is looked at compared with these figures then it certainly does seem worthwhile to operate on patients with cataract and ARM. As a cataract surgeon I have frequently been confronted with patients who were told 10 years previously that they must never let anybody touch their cataract as they had ARM. One of my patients went from being registered blind to returning to drive following cataract surgery having been put off surgery for years! This is unusual but while the jury is out on cataract surgery in the presence of ARM do we as surgeons "also serve who only stand and wait". ${ }^{1}$ I would suggest that we do not serve our patients well by standing and waiting but rather we should discuss honestly the available facts and figures; in this regard the work of Shuttleworth et al is most helpful and I look forward to their next study.

H C SEWARD

Croydon Eye Unit, 33 Mayday Road, Thornton Heath, Surrey CR7 7YE

1 Milton J. "On His Blindness".

2 European Union: Demographic Statistics: Luxembourg: Eurostat, 1991.

3 Evans J, Wormald R. Is the incidence of registrable age-related macular degeneration increasing? Br f Ophthalmol 1996;80:9-14

4 Dickinson AJ, Sparrow JM, Duke AM, et al. Prevalence of age related maculopathy at two points in time in an elderly British population. Eye 1997;11: 301-14.

5 Klein R, Klein E, Wang Q, et al. Is age-related maculopathy associated with cataracts? Arch Ophthalmol 1994;112:191-6.

6 Pollack A, Marcovich A, Bukelman A, et al. Age related macular degeneration after extracapsular cataract extraction with intraocular lens implantation. Ophthalmology 1996;103:1546-54.

7 Van der Schaft TL, Mooy CM, de Brujin WC, et al. Increased prevalence of disciform macular degeneration after cataract extraction with implantation of an intraocular lens. Br f Ophthalmol 1994:78:441-5. 


\section{Deviant axons and glaucomatous damage}

The course of ganglion cell axons from the retina to the optic nerve is predictable and has been known accurately for over a century. The arcuate arrangement of the axons temporally and the presence of the median raphe were first described by the anatomists Michel $^{1}$ and Dogiel ${ }^{2}$ in the latter part of the 19th century. Vogt correctly deduced the arrangement of the superficial nerve fibres in the retina when, in 1913, he observed the retinal nerve fibre layer ophthalmoscopically with the aid of red-free light. ${ }^{3}$ In contrast, the anatomical orientation of retinal nerve fibres within the optic nerve head has been the subject of considerable debate. Before 1930, the common view was that nerve fibres from the peripheral retina entered the central portion of the optic nerve head. ${ }^{4}$ Loddoni established that the reverse was true: nerve fibres from the far retina entered the peripheral optic nerve head while more central fibres occupied a central position in the nerve. ${ }^{5}$ However, the anterior-posterior relation within the retinal nerve fibre layer remained unclear. The work of Wolff and Penman supported the view of the older literature that long retinal axons occupied a scleral position in the nerve fibre layer, while more central axons occupied a vitreal position. ${ }^{6}$ More recent work has supported this view. ${ }^{78}$ Ogden employed highly localised intraretinal injections of horseradish peroxidase in monkey eyes, and elegantly demonstrated that long retinal fibres actually occupy a more vitreal position in the retina and shorter retinal fibres are more scleral in location. ${ }^{9}$ Consequently, at the margin of the optic disc, short and long fibres decussate to match the topographic arrangements of the retinal nerve fibre layer and the anterior portion of the optic nerve head.

The work of Morgan and colleagues, which is reported in this issue of the $B F O(\mathrm{p} 680)$, provides new information about the anatomy of retinal ganglion cell axons as they course through the lamina cribrosa. In their careful study of two human eyes, they found that while the majority of axons took a direct course through the pores of the lamina cribrosa, approximately $10 \%$ deviated from this course and passed between adjacent cribrosal plates. Thus, a substantial minority of axons change trajectory within the lamina and take a more tangential (and perhaps more precarious) course. They found, with the retrograde tracer horseradish peroxidase applied to the freshly cut stump of the retrobulbar optic nerve, that this pattern was present in both central and peripheral portions of the optic nerve head. The existence of such a population of axons highlights the distinction between the apparently precise topographic arrangement of nerve bundles and the rather meandering course that can be taken by individual axons. ${ }^{10}$ This finding suggests the possibility that axons which deviate from a straight intralaminar course might be particularly susceptible to compressive effects because of their tangential trajectory between laminar plates. These deviant axons could thus represent a subgroup of retinal ganglion cells that are selectively damaged in early glaucoma. Other studies have suggested that the special anatomy of the lamina cribrosa region could make humans particularly susceptible to glaucoma. In the disc periphery, the lamina is thicker, and the course of nerve fibres is more curvilinear than at the disc centre. ${ }^{11}$ It has been suggested that the microscopic arrangement of fibre bundles within the lamina cribrosa could play an aetiological role in the pathogenesis of low tension glaucoma. ${ }^{12}$

Apoptosis appears to be a mechanism of retinal ganglion cell death in experimental and human glaucoma. ${ }^{13}$ The molecular triggers for apoptosis in glaucoma are unknown, but may include deprivation of neurotrophic factors, and excitotoxic injury initiated by ischaemia. ${ }^{15}$ If retrograde transport of neurotrophic factors from the central target tissue to the retinal ganglion cells is interrupted at the lamina cribrosa by compression or distortion, it seems reasonable to postulate an apoptotic neuronal cell death. This is a seductive theory, but there is little hard evidence to support this mechanism (or in fact any other mechanism) as a cause of glaucomatous damage. Alternatively, can collapse of laminar plates and distortion of the laminar pores occur secondary to loss of optic nerve fibres within these tissues? The inferior and superior poles of the optic nerve contain fibres that are predominantly damaged in early glaucoma. Are greater numbers of deviant axons located at the inferior and superior poles of the optic nerve head, where early glaucomatous damage selectively occurs? Do these deviant axons belong to any particular class of ganglion cells?

The interesting and important finding reported here by Morgan and colleagues will stimulate discussion about the selective vulnerability of optic nerve fibres. This kind of study is labour intensive, and the results from just two non-glaucomatous eyes have been reported. The authors' findings support the concept that mechanical axon compression can cause glaucomatous optic nerve damage. However, if only $8-12 \%$ of axons show this aberrant trajectory, selective damage to these cells alone is not sufficient to cause glaucomatous visual field loss. Further work will undoubtedly show a great deal of variability among individuals with regard to the proportion of cells that show a deviant intralaminar trajectory. Are there greater numbers of these anomalous fibres in eyes that are susceptible to glaucomatous damage? Histological studies to answer this question may prove difficult to interpret: if fibres are selectively vulnerable, they may appear less frequently in damaged optic nerve heads, or not at all.

The embryological explanation for axon deviation within the optic nerve head becomes relevant in light of this report by Morgan and coworkers. It compels us to reconsider the issue of retinotopic projection of optic nerve fibres and the intermingling of axons from the superficial and deep fibres in the anterior optic nerve head. This intermingling apparently continues throughout the lamina cribrosa, perhaps in an attempt to achieve the correct topographic orientation in the retrolaminar portion of the optic nerve.

This report is a good example of the value of careful observation, even if in only a few specimens. It will undoubtedly stimulate consideration of whether deviant axons represent an anatomical subpopulation that is vulnerable to compressive effects in human glaucoma.

\section{JOSEPH CAPRIOLI}

Jules Stein Eye Institute, UCLA School of Medicine, Los Angeles, CA 90095, USA

1 Michel J. Ueber die Ausstrahlungweise der Opticusfasern in der menschlichen Retina. Beitraege Zur Anatomie Und Physiologie Als Festgabe Carl Ludwig, Leipzig 1874;56-63.

2 Dogiel AS. Veber die nervusen Elemente in der Retina des Menschen. Arch Mikr Anat, Bonn 1891;38:317-44.

3 Vogt A. Die Nervenfaserstreifung der menschlichen Netzhaut mit besonderer Berücksichtigung der Differentialdiagnose gegenüber patholbesonder gischen streifenförmigen Reflexen (präretinalen Faltelungen). Klin
Monatsbl Augenheilkd 1917;58:399-411. Duke-Elder S. Textbook of ophthathol

Vol 1. St Louis: CV Mosby 1944:

5 Peli E, Hedges TR, McInnes T, et al. Nerve fiber layer photography: a comparative study. Acta Ophthalmol 1987;65:71-80. 
6 Yablonski ME, Zimmerman TJ, Kass MA, et al. Prognostic significance of optic disk cupping in ocular hypertensive patients. Am $\mathcal{f}$ Ophthalmol 1980; optic disk cup
89:585-92.

7 Raius RL, Anderson DR. The course of axons through the retina and optic nerve head. Arch Ophthalmol 1979;97:1154-65.

8 Minckler DS. The organization of nerve fiber bundles in the primate optic nerve head. Arch Ophthalmol 1980;98:1630-6. 9 Ogden TE. Nerve fiber layer of the macaque retina: retinotopic

10 Horton JC, Greenwood MM, Hubel DH. Non-retinotopic arrangement of fibres in cat optic nerve. Nature 1979;282:720-2.

11 Dichtl A, Jonas JB, Naumann GO. Course of the optic nerve fibers through the lamina cibrosa in human eyes. Graefes Arch Clin Exp Ophthalmol 1996; 234:581-5.
12 Miller KM, Quigley HA. Comparison of optic disc features in low-tension and typical open-angle glaucoma. Ophthalmic Surg 1987;18:882-9.

13 Quigley HA, Nickells RW, Kerrigan LA, et al. Retinal ganglion cell death in experimental glaucoma and after axotomy occurs by apoptosis. Invest $O p h$ thalmol Vis Sci 1995;36:774-86.

14 Kerrigan LA, Zack DJ, Quigley HA, et al. TUNEL-positive ganglion cells in human primary open-angle glaucoma. Arch Ophthalmol 1997;115:1031-5.

15 Nickells RW. Retinal ganglion cell death in glaucoma:the how, the why, and the maybe. F Glaucoma 1996;5:345-56.

16 Dreyer EB, Zurakowski D, Schumer RA, et al. Elevated glutamate levels in the vitreous body of humans and monkeys with glaucoma. Arch Ophthalmol 1996;114:299-305.

\section{British Fournal of Ophthalmology - http://www.bjophthalmol.com}

Visitors to the world wide web can now access the British fournal of Ophthalmology either through the BMJ Publishing Group's home page (http://www.bmjpg.com) or directly by using its individual URL (http://www.bjophthalmol.com). There they will find the following:

- Current contents list for the journal

- Contents lists of previous issues

- Members of the editorial board

- Information for subscribers

- Instructions for authors

- Details of reprint services.
- BMJ Publishing Group home page

- British Medical Association web site

- Online books catalogue

- BMJ Publishing Group books.

A hotlink gives access to:

The web site is at a preliminary stage and there are plans to develop it into a more sophisticated site. Suggestions from visitors about features they would like to see are welcomed. They can be left via the opening page of the BMJ Publishing Group site or, alternatively, via the journal page, through "about this site". 